\title{
Hematological malignancies: A real challenge to cardiac surgeons
}

\author{
Ahmad K Darwazah \\ Makassed Hospital, Department of Cardiac Surgery Mount of Olives, J erusalem - Israel \\ Correspondence: Ahmad K Darwazah. Address: Makassed Hospital, Department of Cardiac Surgery. Mount of Olives, \\ Jerusalem, Israel. Fax: 97-054-5613-232. E-mail: darwaz30@hotmail.com \\ Received: January 18, 2012 \\ Accepted: May 11, $2012 \quad$ Published: June 1, 2012 \\ DOI : $10.5430 / \mathrm{jhm} . \mathrm{v} 2 \mathrm{n} 2 \mathrm{p} 1$ \\ URL: http://dx.doi.org/10.5430/jhm.v2n2p1 \\ Hematological Malignancies are a group of diseases including various types of leukemia, lymphoma and myeloma. They \\ are characterized by affection of both the lymphatic and hematopoietic systems, as a result they cause immune defects, \\ platelets dysfunction, and hypercoagulability syndrome. These immunocompromised patients are prone to develop \\ various complications including infection, disease transformation, autoimmune complications and increase liability to \\ develop another malignancy.
}

The number of patients with hematological malignancies (HM) who require surgical intervention to treat other associated diseases are increasing due to improvement in the management of these malignancies giving these patients a chance of having a normal life span.

The association of cardiac diseases obviously makes things worse. Management of such patients is often complicated and influenced by the stage of underlying malignancies, previous treatment by chemotherapy or radiotherapy, cardiac status and the risks encountered during surgical intervention.

Coronary artery disease in particular is seen more frequently in patients with HM due to increase aging population. These patients are more liable to develop several morbidities such as bleeding, low cardiac output, myocardial infarction, stroke and renal impairment more than young patients when subjected to cardiac operations.

The modes of treatment used to treat HM are often associated with cardiovascular complications which make the situation more complicated.

Radiation therapy plays a major role in the management of these malignancies. This modality of treatment can be associated with cardiac toxicity and development of a second malignancy especially when combined with chemotherapy ${ }^{[1]}$. Similarly, systemic anticancer treatment has a detrimental effect on cardiovascular system. Chemotherapeutic agents such as trastuzumab, bevacizumab and tyrosine inhibitors are associated with significant risks of cardiovascular complications including heart failure, arrhythmias, conduction disorders, pericarditis, and thrombo-embolic complications ${ }^{[2]}$. 
Beside management complications, the myocardium itself can be affected by these malignancies. Infiltration of the myocardium may occur in leukemia, lymphoma, multiple myeloma and esinophilic syndrome. Such an involvement directly affects management either by reducing, discontinuation, or delay of treatment to avoid cardiac toxicity ${ }^{[3]}$.

The majority of cardiac operations are performed with the aid of cardiopulmonary bypass. Such a technique is known to cause an intense systemic inflammatory response caused by the contact of cellular and humoral blood components with the synthetic material of extracorporal system, leucocyte and endothelial activation, release of endotoxins and surgical trauma itself.

The release of cytokines such as tumor necrosis factor (TNF)-alpha, interleukin (IL)-6, interleukin (IL)-8 and interleukin (IL)-1 play an important role after cardiopulmonary bypass in inducing organ damage by induction of NO synthase and release of large amounts of NO causing tissue injury ${ }^{[4]}$. Most patients exhibit some degree of organ dysfunction, fortunately, such an effect is reversible.

Blood cells in particular are highly sensitive to cardiopulmonary bypass; such a technique is associated with reduction in the number of granulocytes, lymphocytes, platelets, and red blood cells ${ }^{[5]}$.

The experience of performing cardiac operations among patients with HM is limited. Only few patients underwent such procedures. The majority had coronary artery bypass surgery as well as valvular replacement. Previous studies, showed that cardiac surgery can be performed but carries a high incidence of mortality and morbidity ${ }^{[5-11]}$.

The incidence of mortality varied from $0-17 \%{ }^{[5,7,9-11]}$. The cause of death among these immunocompromised patients was sepsis, bleeding and myocardial stunning ${ }^{[5,8,11]}$. Despite improvement of treatment of these malignancies and proper selection of patients to undergo cardiac surgery, morbidity remained high. Its incidence varied from $22 \%-58 \%{ }^{[7-11]}$. In various studies, infection was the commonest complication seen ${ }^{[7,9-11]}$. It varied from superficial wound infection, acute cholecystitis, parodititis to severe mediastinitis, endocarditis and fatal pneumonia ${ }^{[5,7,8]}$.

The high incidence of infection is related to preoperative level of leucocyte and lymphocyte count, shorter duration of the disease, advanced stage of malignancy and low level of gamma globulin ${ }^{[7]}$.

Bleeding is the second common complication. Fecher and colleagues ${ }^{[8]}$ found that $33 \%$ of their patients who underwent coronary artery bypass surgery with or without valve replacement had postoperative bleeding. Such a complication was responsible for high incidence of reoperations and increase use of blood, platelets and fresh frozen plasma.

Other morbidities including myocardial infarction, stroke, respiratory and renal failure were commonly seen among patients who had previous history of radiotherapy or chemotherapy ${ }^{[5]}$.

On analysis of various perioperative factors in relation to morbidity, it was found that older patients were significantly more affected than young ${ }^{[8]}$. Contradicting results were found in relation to platelets number and function ${ }^{[6,8]}$.

The effect of HM on cardiac operations not only influences early results, but long term survival is significantly impaired ${ }^{[5]}$. Progression of malignancies, redo operations, coronary stenting and implantation of defibrillators to treat intractable arrhythmias were among the main causes of mortality and morbidity ${ }^{[8,10]}$.

The effect of cardiopulmonary bypass on tumor spread and progression is unknown. But it is well known that immunity of patients undergoing open heart surgery is affected. Both cell mediated and humoral immunity are temporary affected by cardiopulmonary bypass. The number and properties of granulocytes and lymphocytes are affected, the level of gamma globulin is reduced and the functions of natural killer cells (NK cells) which have a spontaneous cytotoxicity against tumor cells are inhibited during and after bypass ${ }^{[12]}$. The increase release of anti-inflammatory interleukin- 10 by 
cardiopulmonary bypass has been implicated in the suppression of T-cell activity especially cytotoxic T-cells and Th1 cells ${ }^{[13]}$.

Some patients with malignant disease who underwent cardiac operations using cardiopulmonary bypass suffered from progression of their malignancy during follow up ${ }^{[7,8,14-16]}$. The exact mechanism by which some patients behave in that way and not others is not clear. The combined immunodeficiency effect of cancer itself and CPB is a possible explanation.

On the contrary, previous studies suggested that the immunosuppressive effect of CPB does not aggravate the natural course of some HM, but it has a positive effect in reducing the number of patients who require postoperative chemotherapy and increase chemotherapy - free survival time ${ }^{[6]}$. This positive effect was explained by the increased apoptosis of malignant cells by CPB. The reduction of CD4+ lymphocytes after CPB may lead to higher sensitivity towards proapoptotic signals ${ }^{[6]}$.

The application of off-pump technique to revascularize the myocardium among patients with malignancy proved its efficiency ${ }^{[17-19]}$. Contrary to CPB, this technique is associated with a lower release of endotoxins, less activation of neutrophils and compliment and significant lower level of interleukin (IL)-6 and (IL) -10. Subsequently, the incidence of both mortality and morbidity was reduced. The application of this technique among patients with HM is very limited ${ }^{[5,8,17]}$, the incidence of infection, bleeding as well as mortality was reduced ${ }^{[17,20]}$.

Both HM and cardiopulmonary bypass technique which is used to treat associated cardiac disease share a negative impact on both the immune and coagulation systems. This simply explains the high incidence of mortality and morbidity encountered among these patients. Due to limited experience and small number of patients operated upon, no specific rules are found to be applied to all patients in order to reduce such complications. The use of broad spectrum antibiotics, reduction of operation time, platelets-leucocyte plasmapheresis before cardiopulmonary bypass, correction of platelets count by using irradiated platelets, transfusion of fresh frozen plasma and using granulocyte colony stimulating factor may help to guard against complications.

The association of HM and cardiac diseases is a great challenge to hematologist, oncologist and cardiac surgeon. Multidisplinary approach is needed to evaluate and select patients to undergo surgery. Off-pump bypass technique seems to be the most appropriate way to revascularise the myocardium among patients with coronary artery disease.

\section{References}

[1] Kirova Y M, Changari C. Application of new irradiation modalities in patients with lymphoma. Promises and Uncertainties. World J Radiol 2011;28(3):66-69. PMid: 21512653 http://dx.doi.org/10.4329/wjr.v3.i3.66

[2] Senkus E, Jassem J. Cardiovascular effects of systemic cancer treatment. Cancer Treat Rev 2011;37(4):300. PMid: 21126826 http://dx.doi.org/10.1016/j.ctrv.2010.11.001

[3] Allegra A, Alonci A, Russo S, et al. Cardiac involvement in patients with hematological malignancies. J Investig Med 2010;58(7):859-74. PMid: 20683345

[4] Abacilar F, Dogan OF, Duman U, et al. The changes and effects of the plasma levels of tumor necrosis factor after coronary bypass surgery with cardiopulmonary bypass. Heart Surg Forum 2006;9(4):E703-709. PMid:16844625 http://dx.doi.org/10.1532/HSF98.20061012

[5] Sommer S P, Lange V, Yildirim C, et al. Cardiac surgery and hematologic malignancies: A retrospective single center analysis of 56 consecutive patients. Eur J Cardiothorac Surg 2011;40(10):173-78.

[6] Potapov E V, Zurbrugg H R, Herzke C, et al. Impact of cardiac surgery using cardiopulmonary bypass on course of chronic lymphatic leukemia: A case-control study. Ann Thorac Surg 2002;74:384-89. http://dx.doi.org/10.1016/S0003-4975(02)03678-0

[7] Finch S J, Cockerill K J, Jeter J E, Orszulak T A. Coronary artery Bypass Grafting in Patients with chronic Lymphocytic Leukemia. Ann Thorac Surg 1993;55:1192-96 http://dx.doi.org/10.1016/0003-4975(93)90032-D

[8] Fecher A M, Birdas T J, Haybron D, et al. Cardiac operations in patients with hematological malignancies. Eur J Cardiothorac Surg 2004;25:537-40. PMid:15037268 http://dx.doi.org/10.1016/j.ejcts.2003.12.006 
[9] Christiansen S, Schmid C, Loher A, Scheld H H. Impact of malignant hematological disorders on cardiac surgery. Cardiovasc Surg 2000;8(2):149-52. http://dx.doi.org/10.1016/S0967-2109(99)00104-0

[10] Ghosh P, Carroll I, Kauhere A, et al. Cardiac operations in patients with low-grade small lymphocytic malignancies. J Thorac Cardiovasc Surg 1999;118(6):1033-37. http://dx.doi.org/10.1016/S0022-5223(99)70098-X

[11] Samuels L E, Kaufman M S, Morris R J, et al. Open heart surgery in patients with chronic lymphatic leukemia. Leuk Res 1999;2391:71-75.

[12] Tonnesen E, Brinklov MM, Christensen WJ, Olesen As, Madsen T. Natural killer cell activity and lymphocyte function during and after coronary artery bypass grafting in relation to the endocrine stress response. Anesthesiology 1987;67:526-33. PMid: 3499099 http://dx.doi.org/10.1097/00000542-198710000-00014

[13] Markewitz A, Faist E, Lang S, et al. An imbalance in T-helper cells subsets alters immune response after cardiac surgery. Eur J Cardiothorac Surg 1996;10:61-67. http://dx.doi.org/10.1016/S1010-7940(96)80267-3

[14] Darwazah AK, Shehata S. Detrimental effect of cardiopulmonary bypass (CPB) on malignant disease. J Cardiothorac Surg 2011 Feb 4;6:13. PMid: 21294866 http://dx.doi.org/10.1186/1749-8090-6-13

[15] Rao V, Todd TR, Weisel RD, et al. Results of combined pulmonary resection and cardiac operation. Ann Thorac Surg 1996;62(2):342-46. http://dx.doi.org/10.1016/0003-4975(96)00206-8

[16] Danton MH, Anikin VA, McManus KG, McGuigan JA, Campalani G. Simultaneous cardiac surgery with pulmonary resection: Presentation of series and review of literature. Eur J Cardiothorac Surg 1998;13(6):667-72. http://dx.doi.org/10.1016/S1010-7940(98)00088-8

[17] Darwazah AK, Osman M, Sharabati B. Use of off-pump coronary artery bypass surgery among patients with malignant disease. J Card Surg 2010;25(1):1-4. PMid: 19210552 http://dx.doi.org/10.1111/j.15408191.2008.00778.X

[18] Saxena P, Tam RK. Combined off-pump coronary artery bypass surgery and pulmonary resection. Ann Thorac Surg 2004;78(2):498-501. PMid: 15276505 http://dx.doi.org/10.1016/j.athoracsur.2004.02.026

[19] Dyszkiewicz W, Jemielity M, Piwkowski C, et al. The early and late results of combined off-pump coronary artery bypass grafting and pulmonary resection in patients with concomitant lung cancer and unstable coronary heart disease. Eur J Cardiothorac Surg 2008;34(3):531-35. PMid: 18583144 http://dx.doi.org/10.1016/j.ejcts.2008.05.017

[20] Nurozler F, Kutlu T, Kucuk G. Off-pump coronary bypass for patients with concomitant malignancy. Circ J. 2006;70:1048-51. http://dx.doi.org/10.1253/circj.70.1048 